\title{
Redes, gerações e negócios: uma família de imigrantes portugueses na Amazônia.
}

\author{
Networks, generations and business: A family of Portuguese immigrants in \\ the Amazon
}

\author{
Cristina Donza Cancela ${ }^{1}$
}

RESUMO

Trata-se neste artigo de compreender a trajetória de José Antonio Martins, o barão de Monte Córdova, um português que chegou a Belém, capital do Estado do Pará, no período da economia da borracha. Procurase analisar os caminhos da migração e a dinâmica das redes sociais compostas por ele, seus familiares e conterrâneos, observando as estratégias acionadas, a mobilidade, a projeção, os lugares de pertença, as práticas e os jogos de representação negociados nas experiências inscritas no trânsito entre Portugal e Brasil.

Palavras-chave: Imigração portuguesa. Redes. Família. Economia da Borracha. Pará

ABSTRACT

This article examines the trajectory the family of José Antonio Martins, the Baron of Monte Cordova, a Portuguese immigrant who came to Belém, Para, in the period of the rubber economy. Analyze the migration and the dynamics of social networks composed by him, his family and countrymen, watching the strategies, mobility, projection, practices and representation practices and representation entered in transit between Portugal and Brazil.

Keyword: Immigration portuguese. Networks. Family. Rubber economy. Pará

${ }^{1}$ Professora doutora da Universidade Federal do Pará. professora da Faculdade de História da UFPA, do Programa de PósGraduação em História Social da Amazônia e do Programa de Pós-Graduação em Antropologia. pesquisadora PQ-2 do CNPQ. Trabalho financiado pelo CNPQ/CAPES 
Na década de 1850, a borracha começou a agregar valor tornando-se, a partir de 1870, o principal produto da pauta de exportação do Pará (SANTOS, 1980; WEINSTEIN, 1993). A liquidez econômica alcançada com a exportação desse produto foi responsável pela migração para o Estado de indivíduos nacionais e estrangeiros, dentre esses últimos destacavam-se os portugueses.

Foi justamente no início deste período, mais exatamente no ano de 1856 , que se registrou a chegada de José Antonio Martins, um caixeiro de 21 anos de idade, que enriqueceu no período do comércio da goma elástica, vindo a receber o título de barão de Monte Córdova. Ao chegar naquele ano a Belém, capital do Estado do Pará, a cidade ainda não vivia a expressão econômica que viria a ser alcançada a partir da década de 1870 .

Ruas estreitas, carros de boi e iluminação à óleo e querosene ainda faziam parte do cotidiano da urbe, mesmo nas áreas centrais (CANCELA, 2008). Foi nessa cidade que José Antonio Martins aportou, abriu sua própria firma e fez parte de uma rede mais ampla de migração que envolveu seus irmãos, sobrinhos e conterrâneos. Agregou prestígio e visibilidade a seu nome e ao de sua família, participando de firmas comerciais, associações de caráter benemérito e comercial.

Contudo, no início do século XX, quando a borracha ainda estava no seu auge, o barão retornou para sua localidade natal, a freguesia de Santo Tirso, no Conselho de Monte Córdova, Distrito do Porto, localizado ao norte de Portugal. ${ }^{2}$ Faleceu, em sua propriedade, na Quinta das Palmeiras, diagnosticado como demente. É a história desse homem, de suas relações familiares e sociais, das interações estabelecidas em diferentes contextos construindo experiências dinâmicas que vamos tratar nesse artigo. Uma história marcada por redes de sociabilidade que se cruzam em relações econômicas, de parentesco e de nacionalidade, compostas nos locais de origem e de destino no trânsito desses sujeitos entre Santo Tirso e Belém.

É importante destacar que o estudo da imigração portuguesa vai estar presente na historiografia brasileira desde a década de 1980, quando uma série de pesquisas vai tratar de questões como o antilusitanismo e o trabalho (FRUTUOSO, 1989; MENEZES,1996; SILVA,1986; RIBEIRO, 1990). A estas vão se somar estudos que levam em conta as lutas, memórias, associativismo, cultura, sentimentos, participação feminina, legislação e trajetórias de vida. (FONSECA, 2009; GOMES, 2000; LOBO, 2001; MATOS, 2008; MATOS; LEITÃO, 2011; MENDES, 2010; REZNIK; FERNANDES, 2014; ROCHA-TRINDADE; CAEIRO, 2000). Nessa linha de abordagem, esse trabalho se aproxima aos estudos que discutem a imigração portuguesa a partir da compreensão das histórias individuais, dos projetos familiares, das estratégias, das práticas e dos laços de conterraneidade e sociabilidade que atualizam a agência desses imigrantes (MATOS, 2013).

Entendemos que os fragmentos pontuados neste artigo sobre a trajetória de José Antonio Martins, seus familiares e conterrâneos não necessariamente se distanciam das experiências de outros portugueses, já assinaladas pela historiografia que trata da imigração lusa. De qualquer forma, discutir as possíveis aproximações e singularidades da trajetória desses sujeitos nos ajuda a ampliar a compreensão dos múltiplos significados e possibilidades do processo migratório que teve o Pará como destino e a borracha como

${ }^{2}$ A divisão administrativa de Portugal compreende os "Distritos" que agrupam um certo número de "Concelhos" e têm à frente um representante do governo com funções de caráter administrativo. Sobre essa organização (SOUSA; ROCHA, 2014). 
propulsora dos deslocamentos. Buscamos, dessa maneira, evidenciar a densidade das trajetórias, as regularidades, mas também as diversidades de experiências marcadas por diferenças geracionais, de renda, status e projeção social, problematizando a ideia do imigrante generalizado atualizado nos fluxos e perfis de uma abordagem demográfico-econômica.

Para tanto utilizaremos a busca pelo nome (GUINZBURG; CASTELNUOVO; PONI, 1991) nos mais diversos tipos de documentação, tendo claro as possíveis lacunas, omissões e armadilhas de uma narrativa que se propõe a compreender o sujeito inscrito no caráter difuso e justaposto de qualquer trajetória. (BOURDIEU, 2006; LEVI, 2006).

\section{Migração, negócios e redes}

José Antonio Martins chegou a Belém antes da chamada grande imigração, que se inicia na década de 1860, e se intensifica no final do século XIX e início do século XX (LEITE, 2000; LOBO, 2001; PEREIRA, 2002; SERRÃO, 1974). Era filho de Jacinto José Martins, um capitão de milícias e sua esposa, Florinda Rosa Martins, que trabalhava nos serviços domésticos. Não vinha de uma família miserável, mas também não possuía grande fortuna. Foi no Pará que a riqueza desse português se fez através do comércio, da compra de imóveis, ações de bancos e companhias.

Ele chegou à Belém a bordo do vapor Paraense, em 13 de Janeiro de 1856, solteiro, alfabetizado e com 21 anos de idade. ${ }^{3}$ Com esse perfil, José Antonio Martins se somava ao universo amplo de imigrantes portugueses que se deslocaram para o Pará, ao longo de todo o século XIX. Os motivos que possibilitaram e potencializaram a imigração em massa para o Pará são identificados em função do avanço da econômica da borracha, da propaganda governamental de atração de populações europeias, da abertura oficial dos rios amazônicos para a circulação de embarcações estrangeiras e, por fim, das mudanças tecnológicas na linha de transporte entre Portugal e Brasil (CANCELA, 2011). Devemos acrescentar a esses fatores, as transformações capitalistas nas relações de trabalho e de capital ocorridas no campo, na pesca e no artesanato, que tiveram lugar em Portugal (SERRÃO, 1974).

No final do século XIX, o Pará era um dos principais Estados brasileiros a receber imigrantes lusos (CANCELA; BARROSO, 2011). Ao analisar a migração para o Brasil, Serrão aponta o Pará como um dos primeiros destinos dos imigrantes portugueses (SERRÃO, 1974, p. 163-171). Da mesma forma, ao estudar a migração de Fafe e do Porto para o Brasil, Miguel Monteiro destaca o Pará como o terceiro Estado a receber o maior fluxo de migrantes (MONTEIRO, 2000, p. 110). Vale lembrar que a maior parte dos imigrantes portugueses aportados no Estado, advinha da região norte de Portugal, onde se encontravam as cidades

3 As habilitações consulares constituem-se em livros encadernados de registros de súditos portugueses mantidos pelo consulado de cada localidade, e foram criados como uma forma de controle destes nacionais. Sobre a instituição destas habilitações ver: Ministério dos Negócios Estrangeiros. Documentos apresentados às Cortes. Regulamento Consular Português. Decreto de 20 de março de 1855. p.259. 
acima referidas. Uma imigração eminentemente masculina e jovem que permanecia na área urbana, preferencialmente na capital, Belém. Portanto, José Antonio Martins, se enquadra no perfil do português que se deslocou não apenas para o Pará, mas também para outras localidades brasileiras, sinalizando uma trajetória comum a tantos outros imigrantes (SERRÃO, 1974).

Parte desses portugueses alcançou fortuna e visibilidade com o negócio da borracha ou com atividades a ele ligado. Porém, inúmeros ficaram em situação de pobreza, necessitando da ajuda do consulado e das associações beneméritas para retornar a Portugal (HIDAKA, 2013).

Quando José Antonio Martins chegou a Belém, já atuava no comércio, como referiu em seu testamento: "Estou no comércio desde a idade de 11 anos, e vindo para o Pará em 1856, estabeleci-me em 1864 na própria casa onde ainda hoje resido".4

A atividade de comércio destacava-se entre os imigrantes lusos que possuíam algum patrimônio. Quando trabalhamos com os inventários post-mortem dos portugueses residentes em Belém, observamos que cerca de $56 \%$ deles atuavam em atividades comerciais. Ou seja, mais da metade dos indivíduos que possuíam patrimônio e tiveram seus bens inventariados, possuíam firmas comerciais. Os comerciantes somaram os maiores legados levantados, numa faixa de renda que ia de duas a dez mil libras. Portanto, as pessoas desses segmentos comerciais compunham o grupo daqueles com maior nível de riqueza da capital paraense. Como demonstrado em outros trabalhos, em várias localidades brasileiras e em épocas diferentes, a circulação de mercadorias constituiu-se no principal mecanismo de acumulação de riqueza (FRAGOSO, 1998; SAMPAIO, 1997). É importante destacar que muitos comerciantes portugueses, também eram proprietários de firmas de aviamento e consignação de venda de mercadorias e borracha.

Casas aviadoras eram os estabelecimentos comerciais que abasteciam os seringais de mercadorias gerais como alimentos, roupas e utensílios, recebendo, em troca, o pagamento em espécie, mais propriamente em borracha. O dono da casa aviadora intermediava a venda da borracha para a casa exportadora, ou mesmo uma segunda casa de aviação, maior que a sua, da qual ele próprio era aviado. O preço alto cobrado pela consignação de mercadorias aos seringueiros e o baixo preço pago na hora de comprar a produção da borracha eram reclamações constantes desses trabalhadores, que dificilmente conseguiam saldar suas dívidas com a casa aviadora à qual estavam ligados. (REIS, 1953, p. 84).

Esse era o caso de José Antonio Martins que possuía uma firma de consignação de mercadorias. Além da firma, esse imigrante português também era proprietário de imóveis.

${ }^{4}$ Centro de Memória da Amazônia.Fundo: Cartório Odon Rhossard. Inventário de José Antonio Martins. Testamento Transcrito a partir do Inventário, ano 1907. (grifo nosso). 
Vale lembrar que a intensa presença de rentistas urbanos entre os comerciantes portugueses tem a ver não apenas com a rentabilidade desse negócio em uma cidade em crescimento econômico e urbano, mas também com aquilo que Fragoso chamou de "ideal aristocratizante" que passa pela tentativa de distanciamento dos indivíduos do mundo do trabalho. (FRAGOSO, 1998).

Se muitos foram os portugueses que possuíam firmas e imóveis, diminuto foi o número daqueles que declararam possuir terras, engenhos e fazendas, num total de apenas $9 \%$ dos inventariados (CANCELA et al., 2013). ${ }^{5}$ As atividades ligadas ao plantio e a criação de gado permaneciam preferencialmente em meio às famílias locais, restando aos imigrantes a busca pela riqueza através da atividade comercial (KUZNESOF, 1989). Esse foi o caminho seguido por José Antônio Martins, que, ao eleger o Pará como destino, se somava a um conjunto de comerciantes portugueses oriundos de Santo Tirso, que realizaram o mesmo trajeto. Comerciantes com capital simbólico na freguesia, que ganharam notoriedade e riqueza a partir dos negócios realizados no além mar. Um dos nomes de destaque com esse perfil era o do conde de São Bento, Manoel José Ribeiro. Filho de caseiros, ele chegou ao Pará ainda no ano de 1819, tendo enriquecido com o comércio e se transformado em um dos maiores beneméritos de Santo Tirso (PEREIRA, 1984). Outros comerciantes de menor prestígio, mas igualmente enriquecidos e constantemente noticiados no jornal de Santo Tirso, podem ser citados, como Francisco Martins da Costa e Joaquim Maria Leite. Desse modo, ao migrar para o Pará, José Antonio Martins seguiu caminhos já trilhados por outros bem sucedidos homens de negócio da mesma localidade.

Em Belém, passados alguns anos como caixeiro, José Antonio Martins abriu duas firmas. Da primeira temos pouca informação, sabendo apenas que faliu. A segunda firma era de consignação e comissão de mercadorias, em sociedade com outro português de Santo Tirso acima referido, Joaquim Maria Leite. É o próprio José Antonio Martins que nos informa em seu testamento:

\footnotetext{
Tive negócios grandes de importação do estrangeiro e de exportação, sob a razão social de Martins \& Companhia, cuja firma somente subsiste para certas liquidações de pouca valia. Hoje tenho sociedade com Joaquim Maria Leite, casado, português, sob a razão de Leite \& Companhia para o negócio de comissões do interior. Os meus haveres constam do meu capital nessa firma, hoje constituída e de papeis de crédito, como ações de bancos e companhias e de bens de raiz nesta cidade e em Portugal; os haveres particulares nesta ficam desde hoje entregues ao dito meu sócio Leite a guardar títulos e tudo mais, nos cofres da nossa firma. ${ }^{6}$
}

5 Os números acima foram obtidos a partir de um total de 464 inventários do Centro de Memória da Amazônia, cartório Odon Rhosard, no período de 1870 a 1920.

${ }^{6}$ Centro de Memória da Amazônia. Fundo: Cartório Odon Rhossard, Ano 1907, Inventário de José Antonio Martins . Testamento transcrito a partir do Inventário. 
Temos aqui dois negociantes de uma mesma localidade portuguesa, se deslocando para o Pará e rearticulando suas experiências e negócios, atualizando uma rede no local de destino que passava pela origem em comum.

As relações entre o futuro barão de Monte Córdova e Joaquim Maria Leite eram estreitas. Em seu testamento, o barão elegeu o sócio como seu primeiro inventariante, à frente do irmão, Constantino José Martins. Como seu terceiro inventariante, apareceu o também comerciante português, Domingos José Dias, conhecido como visconde de São Domingos.7 Muito embora, Domingos José Dias não fosse de Santo Tirso, era de uma freguesia próxima, localizada ao norte de Portugal, na província minhota de Braga. Vemos, assim, os laços de conterraneidade, afinidade e negócios sendo atualizados por esses imigrantes.

Não sabemos de que forma José Antônio Martins foi amealhando sua fortuna, formada por uma firma comercial, dois prédios assobradados, dois prédios de porta e janela, onze terrenos, ações de banco e apólices da dívida externa do município de Belém. ${ }^{8}$

Cerca de 30 anos após sua chegada à Belém como caixeiro, ele já possuía riqueza suficiente para receber/comprar um título nobiliárquico. Assim é que, no ano de 1887 , ele passa a assinar como barão de Monte Córdova. Pelo título pagou o relativo a setecentos e vinte mil reis de direitos de mercê e sessenta e três mil reis de selo, no reinado de Dom Luis I. 9 Para se ter referência do quanto isto valia à época, o preço pago pelo título correspondia a pouco menos do valor de um escravo do sexo masculino, com ofício. Vale destacar que os escravos estavam entre os "bens" de maior valor dos inventários (CANCELA, 2011).

Apesar de nesse momento a concessão de mercês pelo Estado ser um recurso importante para os cofres públicos, ou ainda, a compra de títulos se encontrar vulgarizada, permitindo a um maior número de negociantes e capitalistas o acesso a um título de nobreza, a obtenção de uma mercê era fator de distinção e agregava capital simbólico aqueles que o recebiam.

Mesmo com o número elevado de comerciantes portugueses em Belém, encontramos poucos deles com títulos de ordem militar, religiosa e/ou nobiliárquica. Esse fato pode significar o desinteresse dos homens de negócio na obtenção dessas mercês, até mesmo por que elas vinham carregadas de custos financeiros. Mas também pode significar que, talvez por esse mesmo motivo, a obtenção de uma mercê trouxesse um lugar de pertença diferenciado, de distinção e de prestígio, mesmo que não agregando o mesmo capital simbólico de outrora (VASCONCELOS, 2003).

De todo modo, a obtenção do título resultava da condição social privilegiada, potencializando essa condição, dando visibilidade à riqueza do sujeito, deixando claro a sua distinção e a construção de um espaço social diferenciado, uma hierarquia bem demarcada, agregando posição simbólica e configurando-se em um emblema de pertencimento (BOURDIEU, 1973, p. 66). Assim, José Antônio Martins, passou a ser conhecido como o Barão de Monte Córdova, um rico comerciante com inserção e projeção social na capital paraense e

7 Domingos José dias passou a assinar com o título de Visconde de São Domingos após o recebimento de mercê do rei Dom Carlos I, em 18 de abril de 1892. Arquivo da Torre do Tombo. Registro Geral de Mercês. Dom Carlos I, livro 3, fl 184.

${ }^{8}$ Centro de Memória da Amazônia. Fundo: Cartório Odon Rhossard, Ano 1907, Inventário de José Antonio Martins.

9 Arquivo da Torre do Tombo. Registro Geral de Mercês, Dom Luis I, livro 46, folha 46. 
em Portugal, associando-se aos segmentos da elite, pois para fazer parte desse grupo é necessário aliar status e poder à riqueza material (BURKER, 1990; HEINZ, 2006).

Muitos desses comerciantes construíram sua inserção, prestígio e projeção através das redes familiares e comerciais, passando a apoiar e fazer parte da direção de associações de classe, bem como, associações nacionais de caráter benemérito, de lazer e esportivo (IMÍZCOZ, 2004). A participação em associações como essas além de acionar relações de convívio entre os conterrâneos, demarcavam a tentativa de manter os laços sociais e culturais com a pátria, no que diz respeito à identidade, à língua, aos acontecimentos e, também, à assistência mútua, inclusive de imigrantes desvalidos (AVELINO, 2013; FONSECA, 2009; MELO; SILVA, 2009). Além, é claro, de agregar status, projeção e visibilidade àqueles que delas participavam.

O Barão de Monte Córdova estava presente nessas instituições associativas. Ele foi um dos provedores da Beneficente Portuguesa, uma das instituições mais importantes criadas pela comunidade portuguesa não apenas em Belém, mas em várias localidades brasileiras (AVELINO, 2013). Ele foi eleito para a mesa da assembleia geral da Beneficente Portuguesa nos anos de 1874 e 1875. Chegou a ser presidente da sua gerência no ano de 1892 (O Pará e a colónia portuguêza, 1920). Estes fatos indicam sua participação ativa nos espaços de socialização portuguesa criados na cidade, e uma inserção que ia para além da condição de sócio, assumindo funções na diretoria e na presidência, marcando presença naquilo que comumente era chamado de colônia Portuguesa no Pará. ${ }^{10}$

É interessante observar o constante uso da palavra colônia nos mais diversos documentos produzidos pelos imigrantes nesse período. A utilização dessa palavra sugere a representação que estes sujeitos possuíam de si. Um estar aqui-Pará, mas também um estar lá-Portugal. O jogo entre presente e passado marcado pela distinção de origem de um nós que vive há vários anos e, muitas vezes se casa, tem filhos, negócios e bens em Belém, mas não é do lugar. Que se mistura e, ao mesmo tempo, se distingue pontuando a diferença com um eles, neste caso, os brasileiros.

Por outro lado, a palavra colônia aciona representações de uniformidade e homogeneidade entre os portugueses residentes no Pará. Afirma um sentido de unidade e solidariedade, uma espécie de comunidade imaginária (ANDERSON, 2008) construída a partir do pertencimento a uma nação: Portugal. As associações que concentram os indivíduos pertencentes a essa "colônia", consolidam práticas e criam sentido de pertença, com fronteiras definidas em relação aos outros, os nativos, e, paralelamente a isso, matizam as diferenças, assimetrias e hierarquias entre os imigrantes portugueses que aportaram em terras paraenses. Apoiam-se na ideia de uniformidade de uma suposta colônia a despeito das disputas, conflitos e assimetrias efetivamente existentes e que podiam ser percebidas, por exemplo, nos constantes desentendimentos ocorridos durantes as eleições de diretoria da Beneficente Portuguesa, em que as alianças, disputas e rompimentos se manifestavam (CRUZ, 1996).

\footnotetext{
${ }^{10}$ Encontramos o uso do termo colônia portuguesa em vários livros, jornais e matérias produzidos no período estudado, ou próximo a ele. Assim, temos a obra já referida: O Pará e a colónia Portuguêsa. Belém: typographia da Livraria Gillet, 1920; o Álbum da colônia Portuguesa no Brasil. Organizado por Teófilo Carinhas e publicado pela oficina "Gráficas do Número" de Carinhas \& Cia Ltda, onde consta uma parte dedicada à presença portuguesa no Pará; Os jornais: Lusitano, que depois recebe o título de $A$ colônia(1923-1928); Jornal O Portugal, que se intitulava o "orgam da colônia lusa no Norte do Brazil" (1918).
} 
A inserção do barão de Monte Córdova, na sociedade belenense, também se estendeu às instituições de caráter econômico existentes na cidade. Ele participou da organização da Associação Comercial do Pará, no ano de 1885, quando compôs a diretoria da mesma, que à época chamava-se Praça do Comércio (CRUZ, 1996). Seu sócio e conterrâneo, Joaquim Maria Leite, também integrou a Associação e esteve presente na primeira reunião ocorrida no ano de 1899, quando a então antiga Praça do Comércio, criada no ano de 1864, mudou o nome para Associação Comercial do Pará. Joaquim Maria Leite também fez parte do conselho deliberativo de várias diretorias daquela instituição (CRUZ, 1996, p. 187).

Vemos a inserção desses dois comerciantes de Santo Tirso nas esferas associativas voltadas para a defesa dos interesses dos comerciantes no Pará, muitos deles portugueses. Esta prática evidencia não apenas os laços de conterraneidade, mas também a visibilidade, o prestígio e o status que o barão e seu sócio possuíam neste cenário, atuando não apenas como membros, mas também como diretores e sócios fundadores da Associação Comercial do Pará. A presença nessas associações atualizava e potencializava a sociabilidade e projeção em meio aos demais imigrantes, assim como, à sociedade local. Da mesma forma, ao criar esses espaços associativos institucionalizados de convívio, os imigrantes criavam raízes mais duradouras junto à sociedade que lhes serviu de destino. Um estar aqui-Pará, pontuado por longos anos de intersecções sociais, sem contudo deixar de acionar marcadores da diferença com a sociedade local, num ser de lá-Portugal, atualizado em diversas práticas e formas de identificação, em que a participação em associações de caráter nacional é um exemplo.

É nesse jogo que a trajetória e o discurso identitário desses imigrantes se constroem, em interações sociais dinâmicas onde, ora as diferenças em relação aos locais são acionadas, ora são matizadas e (re)criadas.

Para imigrantes como José Antonio Martins, o Pará não parece ter sido apenas um lugar de trânsito, um porto de chegada, enriquecimento e retorno para a cidade natal. O Estado também se conformou como um local onde estes portugueses se estabeleceram, viveram longos anos, criaram laços sociais, projetaram seus negócios e nomes, participaram de instituições que os sociabilizavam e os imbricavam mais densamente à sociedade local, atualizando e consolidando uma imagem de si nesta sociedade, que por vezes passava, paradoxalmente, pela reafirmação da identidade nacional e da noção de colônia portuguesa.

\section{Família, migração, projeção e retorno}

As relações e redes montadas no Estado do Pará pelos imigrantes ultrapassavam a esfera das associações e dos negócios, alcançando as relações familiares e matrimoniais iniciando e organizando novas interações no lugar de destino, redefinindo e reestruturando aquelas existentes em Portugal. 
Assim, a família de José Antonio Martins foi se deslocando aos poucos para o Pará, em datas diferenciadas. Eles eram oito filhos, sendo quatro homens e quatro mulheres. Os três homens mais velhos, migraram para o Pará. As filhas mulheres e o irmão mais novo permaneceram em Portugal, o que nos faz pensar em uma estratégia familiar de deslocamento apenas dos filhos varões e a permanência das mulheres e do filho pequeno na freguesia.

A família Martins seguia assim, uma prática comum que se verificava em Portugal, de permanência das mulheres no país, responsável pela migração em menor escala das mesmas. As representações em torno da mulher solteira que migrava eram carregadas de conotação negativa, sendo-lhes atribuídas imagens de mulher de vida fácil e desregrada. Essas representações tornavam-se um obstáculo para um futuro casamento. Ao mesmo tempo, pesava negativamente para a família a migração de uma filha, pois era sinal de pobreza dos pais ter que chegar a tal expediente (BRETTELL, 1991).

Desse modo, aquelas famílias com um pouco mais de recurso procuravam evitar a migração de suas filhas. Seguindo essa prática, apenas os três irmãos da família Martins migraram. Se o irmão mais velho, José Antonio Martins chegou ao Pará ainda em 1856, o irmão mais novo, Constantino José Martins, só migrou doze anos depois, em 7 de novembro de 1868. Não sabemos a data de chegada a Belém do terceiro irmão, Manoel Martins Pinto.

O Barão de Monte Córdova nunca casou, nem teve filhos. Porém seu irmão, Constantino José Martins casou-se com uma paraense, Etelvina de Abreu e Mello, da cidade de Bragança, interior do Estado do Pará. ${ }^{11}$ Tal como José Antônio Martins, Constantino também chegou como caixeiro, no ano de 1868 e, tornou-se um rico comerciante. ${ }^{12}$ Assim como seu irmão, chegou à Belém antes do boom da borracha, e permaneceu na cidade nos anos em que esta economia se consolidava.

O mesmo ocorreu com o terceiro irmão que migrou para o Pará, Manoel José Martins Pinto. Não sabemos a data de sua chegada, contudo, quando de seu falecimento no ano de 1895, ainda possuía firma em Belém, sob a razão Martins Pinto \& Alves, que abriu no ano de 1889. Era uma firma de importação, consignação e comissão de produtos nacionais e estrangeiros. A firma era em sociedade com dois outros portugueses, Antonio Rodrigues Alves e Antonio Guimarães. ${ }^{13}$ Manoel faleceu na Ilha da Madeira, quando viajava em direção à Lisboa. Naturalizou-se brasileiro e era casado com Emilia Aurora Friães Martins. ${ }^{14}$

É importante destacar que, embora estivessem no Pará em períodos que coincidiam, os três irmãos tinham firmas independentes, não formaram sociedade entre eles, e sim, com outros portugueses. No caso do Barão de Monte Córdova, a sociedade era com um comerciante da mesma localidade de origem, Joaquim

\footnotetext{
${ }^{11}$ Registro de casamento de Constantino José Martins e Etelvina de Abreu Mello. Basílica de Nazaré. Livro de Matrimônios, rolo 5 , folha $5(f)-(v)$.

12 Habilitação consular Constantino José Antonio Martins. Arquivo do Grêmio Literário Português. Banco de dados Grupo de Pesquisa "População, Família e Migração na Amazônia-RUMA"/ Centro de Memória da Amazônia-CMA. Código da habilitação: 1873. Registro 3099. Imagem: p1480814

${ }^{13}$ Centro de Memória da Amazônia. Fundo: Cartório Odon Rhossard, Ano 1895, Inventário de Manoel Jose Martins Pinto.

${ }^{14}$ Centro de Memória da Amazônia. Fundo: Cartório Odon Rhossard, Ano 1895, Inventário de Manoel Jose Martins Pinto. Certidão de óbito transcrita do Inventário.
} 
Maria Leite. Já Manoel tinha como sócio, Antônio Rodrigues Alves, português do Concelho de Ponte de Lima, na região Minhota, ao norte de Portugal. ${ }^{15}$

Mesmo tendo migrado para o Pará, se estabelecido comercialmente e, no caso de Constantino, casado com uma mulher paraense, tanto o barão como seu irmão Constantino voltaram para a terra de origem, a freguesia de Santo Tirso, no início do século XX. No momento do retorno dos irmãos Martins, a borracha ainda mantinha sua hegemonia na pauta de exportação e a crise não assolava a economia local, o que viria a ocorrer somente a partir do ano de 1910. Portanto, o retorno ocorreu em pleno auge da goma elástica, quando os negócios ainda se beneficiavam da alta do preço de exportação desse produto. Desse modo, a crise econômica não estava entre os motivos do retorno da família Martins.

Mesmo voltando para a sua propriedade denominada Quinta da Palmeira, em Santo Tirso, o barão manteve a firma aberta em Belém, assim como os bens e as propriedades. Nem sempre o retorno marcava a ruptura com os negócios e as redes sociais compostas na cidade de destino.

O terceiro irmão, Manoel, faleceu ainda em 1895, portanto não temos como saber se ele seguiria os passos dos dois irmãos e retornaria a Portugal. Porém, após seu falecimento, a esposa Emilia Aurora Friães Martins, retornou para Santo Tirso, juntamente com seus filhos e o dinheiro da liquidação da firma do marido.

Vemos assim que, a despeito das relações sociais construídas após vários anos de residência, em meio à criação de firmas, compra de bens, participação em associações, matrimônio e naturalização, a primeira geração da família Martins não permaneceu no Pará, retornando para Portugal. Mas, o que parecia ser o fim das relações criadas no além mar, foi o caminho para a imigração das novas gerações daquela família, como veremos mais à frente.

Uma vez em Santo Tirso, a primeira geração da família Martins agregou lugar de destaque e prestígio local. O nome de Constantino José Martins, o irmão do barão, podia ser encontrado nas matérias do jornal da freguesia, citado como comerciante e benemérito. Em matéria datada do ano de 1902, publicada no jornal de Santo Tirso, se fazia uma chamada para que, os artistas de pedreiro se apresentassem para a construção da torre da Igreja de Monte Córdova. A matéria destacava: "Há tempos que este jornal noticiou que o exm. Sr. Constantino José Martins deu espontânea e cavalheirosamente avultada quantia de $200 \$ 000$ réis para ajuda de se fazer uma torre na egreja de Monte Córdova". ${ }^{16}$

O mesmo Constantino era citado em pequenas notas sociais, comuns na estrutura do Jornal de Santo Tirso, onde se tornava público acontecimentos da vida de pessoas expoentes do local. Viagens, chegadas, formaturas, assunção de cargos públicos, doenças e recuperações, eram temas recorrentemente noticiados no periódico.

\footnotetext{
15 Habilitação consular Antonio Rodrigues Alves. Arquivo do Grêmio Literário Português. Banco de dados Grupo de Pesquisa "População, Família e Migração na Amazônia-RUMA"/ Centro de Memória da Amazônia-CMA. Código da habilitação: 5467. Registro 5168. Imagem: p1450321.

${ }_{16}$ Jornal de Santo Tirso, 1.05. 1902. N.52, fl.o3.
} 
Em uma dessas notas, o nome de Constantino José Martins foi citado: "Acha-se quase estabelecida de grave enfermidade que actualmente a acometeu, a exma , esposa do nosso amigo snr Constantino José Martins, da Quinta do Leigal". ${ }^{17} \mathrm{E}$, na sequência, na coluna de anúncios encontramos: "Constantino José Martins agradece ao médico Arnaldo Baptista Coelho o restabelecimento de sua esposa D. Etelvina D'Abreu Mello Martins". ${ }^{18}$

Notas sobre o barão também não eram incomuns no jornal de Santo Tirso. O fim de sua firma no Pará, que aconteceu após alguns anos do seu retorno para Santo Tirso, no ano de 1902, foi matéria de página inteira do jornal, onde se lia o traslado do encerramento. ${ }^{19}$

A doença que atingiu o barão, sua interdição para gerir seus negócios e os conflitos em torno desse fato, também podiam ser conhecidos a partir das páginas do periódico. O Jornal noticiou que o barão estava entregue a uma "tutela extrajudicial, para não lhe darmos um nome mais feio" e que isto era "um crime", um "cárcere privado que atingia o barão e parte de sua família", dando a entender que a ação foi movida por outra parte da família. ${ }^{20}$ As notícias seguem falando dos "crimes causados pela cobiça e inveja que brotaram da fortuna do infeliz barão de Monte Córdova", segundo José Gomes, que assinava a matéria e era cunhado do barão, o crime constituiu-se na abertura de uma ação de despejo movida contra ele, José Gomes. A ação teria sido assinada por José Antonio Martins, porém, a sua revelia, pois ainda segundo o autor da matéria, o próprio barão negara ter assinado o documento. José Gomes conclui afirmando que aquilo era uma violência contra o barão "porque a pessoa em nome de quem sou perseguido é infelizmente, n'este momento, arguida numa acção de interdicção por demência". ${ }^{21}$

No ano seguinte, uma nota do mesmo jornal destacava que "já se encontra n'esta freguesia e na sua formosa e fidalga quinta, o Exmo. Sr. Barão de Monte Córdova". ${ }^{22}$ Era o ano de 1903, quatro anos depois o barão viria a falecer demente naquela mesma Quinta da Palmeira.

A morte do barão de Monte Córdova foi notícia de destaque nos jornais de sua freguesia, mas também da cidade do Porto. Dois, dos maiores jornais do Porto em circulação, noticiaram seu falecimento.

O Jornal Diário de Notícias assinalou sua morte com uma pequena biografia acompanhada de uma ilustração do rosto do barão, em destaque na segunda página do jornal. A notícia afirmava que José Antonio Martins falecera em sua Quinta da Palmeira, em Santo Tirso, que possuía 200 reis em contos fortes e que os termos de seu testamento ainda eram desconhecidos, visto que este se encontrava no Pará. Acerca do enterro a matéria ressaltava "a grande audiência do mesmo", e o fato do barão ter "recebido seu título do rei Dom Luiz, e que fizera fortuna no Pará". ${ }^{23}$

\footnotetext{
${ }^{17}$ Jornal de Santo Tirso, 19.06.1902. n. 7, fl,02.

${ }_{18}$ Jornal de Santo Tirso, 3.07.1902, n.9, fl.03.

19 Jornal de Santo Tirso, 4.02.1902, n.18, fl.o3

${ }^{20}$ Jornal de Santo Tirso, 20.11.1902, n.29, fl 03

${ }^{21}$ Jornal de Santo Tirso,4.12.1902.n. 31, fl.o2.

22 Jornal de Santo Tirso, 28.05.1903, n.4, fl 02.

23 Jornal Diário de Notícias. 18.01.1907. n.16, fl 02.
} 
No Jornal Commercio do Porto, seu falecimento foi noticiado na primeira página do periódico, e trazia o mesmo conteúdo do Jornal Diário de Notícias, acrescentando apenas que o Barão "estava interdicto, há tempos, por não se achar no pleno uso da razão" 24

Por sua vez, o Jornal de Santo Tirso publicou o que chamou de uma pequena biografia da vida do Barão:

Na sexta-feira, às ghoras da noite, exalou o ultimo suspiro, na sua magnifica quinta de recreio da Palmeira, o saudoso titular barão de Monte Cordova, que adoptou como título a freguesia de sua naturalidade[...] Interdictdo por demência e depois prostado no leito por doença, passou nos últimos dias de sua existência uma vida amargurada. A fortuna ora lhe foi favorável, ora adversa.

Fez atingir uma prosperidade admirável uma casa comercial importante que fundou no Pará, adquirindo uma grande fortuna; porem a adversidade aniquilou dentro em pouco tempo o fructo de seu laborioso trabalho.

De rico que era ficou outra vez pobre; porem não extrahou nem desanimou. Dispondo de muito credito e de muitas atividades, auxiliado por um guarda livros exemplar pôde dentro em poucos anos recuperar uma nova fortuna para poder viver na opulência, na sua querida pátria.[...]

O ilustre extincto possuidor de uma avultada fortuna deixou testamento que se acha depositado no banco do Para. ${ }^{25}$

Mesmo tendo se retirado do Pará, o falecimento do barão foi divulgado na capital paraense, em uma nota publicada em um dos jornais de maior circulação local, a Folha do Norte:

Registro fúnebre

Por telegrama expedido hontem de Santo thirso (Portugal) para a firma comercial desta praça Alves Braga \& Cia soube-se ter falecido naquela cidade o snr. José Antonio Martins, barão de Monte Cordova.

O EXTINCTO CONTAVA 70 ANNOS DE EDADE E FORA, POR MUITOS ANOS, COMERCIANTE NESTA CAPITAL, SENDO CHEFE DA EXTINCTA FIRMA MARTINS \& CA., HOJE SUCEDIDA PELA DE LEITE \&

24 Jornal Commercio do Porto. 15.01.1907. n.13, fl 01

25 Jornal de Santo Tirso, 17.01.1907, n.37. 
CIA.

O snr. Barão de Monte Cordova era solteiro, deixando apenas nesta capital um sobrinho, que é o estimável moço sr. Armando Pinto, auxiliar dos srs. Alves Braga \& cia. ${ }^{26}$

A estratégia de migração de Portugal para o Pará da família Martins, se manteve com a segunda geração. Armando Martins Filho, foi um deles. Era filho do falecido Manoel Antonio Martins e chegou à cidade no período de auge da economia da borracha, quando a liquidez econômica ainda se mantinha.

Armando já havia vivido em Belém, ainda pequeno quando o pai era vivo. Após o falecimento de seu pai no ano de 1895, sua mãe, Emilia Aurora Friães Martins, abriu o inventário dos bens da família, liquidou os negócios do marido na capital paraense e retornou para Santo Tirso com os filhos menores: Armando, Florinda e Armênia. ${ }^{27}$

Nove anos depois, Armando volta à Belém, no ano de 1904. Chegou à cidade com a idade de 23 anos e solteiro. Saiu de Portugal através do Porto de Leixões, Concelho de Matosinhos, cidade pertencente ao Distrito do Porto, a bordo do vapor Obidense. ${ }^{28}$

Mais uma vez, assim como ocorreu com a primeira geração da família Martins, apenas o filho varão migrou. As mulheres, mais exatamente suas duas irmãs e a mãe, permaneceram em Santo Tirso.

Quando Armando migrou para o Pará, sua família já possuía nome e prestígio na cidade portuguesa de Santo Tirso. Sua viagem foi noticiada nos jornais locais com destaque:

Seguiu ontem no comboio expresso para o Porto, indo embarcar a Leixões, com destino ao Pará, o nosso presadissimo amigo e conterrâneo snr Armando Martins Pinto, filho da exma. Sra. D. Emilia Aurora Friâes Martins. [...] O nosso presado amigo, que como dissemos parte para o Pará, vae ali dedicar-se à carreira commercial para que tem decidida vocação e Ihe não falta tino e inteligência sendo por isso de esperar que a fortuna lhe corra prospera, como ardentemente lhe desejamos. ${ }^{29}$

\footnotetext{
${ }^{26}$ Jornal Folha do Norte, 13.01.1907. n. 3295.

${ }^{27}$ Centro de Memória da Amazônia. Fundo: Cartório Odon Rhossard, Ano 895, Inventário de Manoel Jose Martins Pinto.

${ }^{28}$ Habilitação consular Armando Martins Pinto. Arquivo do Grêmio Literário Português. Banco de dados Grupo de Pesquisa "População, Família e Migração na Amazônia-RUMA"/ Centro de Memória da Amazônia-CMA. código 9191. Habilitação 2635. Imagem P1000125. Data da habilitação: 07/07/1908.

29 Jornal de Santo Tirso, 17.11.1903, n⿳0.28, fl.03.
} 
Após alguns anos residindo em Belém, Armando casou-se. Era o ano de 1911. O enlace se deu com Maria Luisa Veloso. Ela tinha 18 anos de idade e ele, segundo a certidão, $26 \operatorname{anos}^{30}$. Embora Maria Luisa Veloso fosse paraense, ela era filha de um comerciante português, Luiz Gonçalves Veloso, proprietário da firma Almeida Martins e Companhia..$^{31}$ Deste modo, o casamento de Armando com Maria Luisa, configurou-se em uma composição matrimonial entre famílias de mesma nacionalidade, atualizando uma homogamia oculta (TRUZZI, 2004), e a rearticulação da rede de nacionais nas sociedades de destino.

A família de Maria Luisa vivia há tempos no Pará. Suas quatro irmãs e um irmão nasceram todos no Estado. Seu pai, o comerciante Luiz Velloso, já era falecido quando a filha se casou.

A despeito da matéria do Jornal de Santo Tirso desejando o breve retorno de Armando, este nunca voltou em definitivo para Portugal. Ele faleceu, ao que tudo indica, no Pará, e Maria Luisa Veloso, voltou a casar-se no ano de 1922, desta feita, com um cearense. Do casamento com Armando não teve filhos.

Mais dois sobrinhos do barão de Monte Córdova também viveram em Belém. José e Manoel, filhos de Tomás, o irmão mais novo do barão que até onde sabemos nunca migrou para o Pará. Uma vez na cidade, trabalharam no comércio, mais exatamente na firma de Antonio Rodrigues Alves, sócio do tio falecido, Manoel. Assim como os irmãos Martins, Antonio Rodrigues Alves chegou à Belém como caixeiro, com idade de 19 anos, no período inicial da economia da borracha, no ano de $1874 .{ }^{32}$ Vemos aqui a rede se rearticulando e entrelaçando gerações de migrantes. A despeito do retorno da primeira geração para Santo Tirso, a segunda geração volta ao local de destino, Belém, e tem como referência um imigrante português conhecido da família, ex-sócio de um de seus integrantes, mantendo e recriando os laços comerciais, de sociabilidade, conterraneidade e afinidade anteriormente criados.

Quando da morte do barão de Monte Córdova, em 1907, os sobrinhos, José e Manoel, foram indicados pelo tio Constantino, para encaminhar o inventário dos bens do barão ainda existentes em Belém. ${ }^{33}$

O patrimônio do barão de Monte Córdova foi avaliado em 406:366\$020(quatrocentos e seis contos e trezentos e sessenta e seis mil e vinte réis). Eles foram todos legados às suas irmãs e ao irmão Constantino, bem como seus sobrinhos, fossem aqueles residentes em Santo Tirso, fossem os que viviam em Belém. Um de seus sobrinhos, Américo Martins Monteiro de Mattos, dois anos após o falecimento do barão de Monte Córdova, dedica-lhe a dissertação apresentada junto a Escola Médico-Cirúrgica do Porto, em sinal de agradecimento. A mãe e o pai também são mencionados na dissertação de Américo, mas somente o título nobiliárquico do barão é textualmente referido, sugerindo um lugar de distinção da família Martins e a significação que o título ainda carregava.

\footnotetext{
$3^{30}$ Registro civil de casamento Armando José Martins e Maria Luisa Veloso. Cartório Privativo de casamento, ano 1911. Arquivo: Centro de memória da Amazônia/CMA.30.08.1900.

${ }^{31}$ Centro de Memória da Amazônia. Fundo: Cartório Odon Rhossard, Ano: 1900. Inventário de Luiz Gonçalvez Veloso.

${ }^{32}$ Habilitação consular Antonio Rodrigues Alves. Arquivo do Grêmio Literário Português. Banco de dados Grupo de Pesquisa "População, Família e Migração na Amazônia-RUMA"/ Centro de Memória da Amazônia-CMA. código 5168 . Habilitação 5467. Imagem: p1450321. Data da habilitação: 31/12/1881.

33 Centro de Memória da Amazônia. Fundo: Cartório Odon Rhossard, Ano 1907, Inventário de José Antonio Martins.
} 
Além dos parentes, em seu testamento o barão deixa legados para a Santa Casa de Misericórdia do Pará, a Ordem Terceira de São Francisco, no Pará, e ao seu Barbeiro, Martiniano, pois, segundo o barão, "é seu freguês mais antigo". ${ }^{4}$ Uma última lembrança daqueles que ficaram no Pará e das instituições de caridade do Estado, valorizando as relações sociais construídas na cidade de destino, visibilizando as redes efetivas e afetivas que nela criou nos caminhos da migração.

É importante observar que, a despeito de estarmos nos referindo a José Antonio Martins e seus familiares como (e)imigrantes, em momento algum essa representação é acionada nas matérias de jornais que consultamos a respeito da família Martins, ou de outros indivíduos a ela relacionados. É como se o (E)Imigrante fosse sempre o outro, os inúmeros pobres, analfabetos, pescadores, artesãos e camponeses, que embarcavam cada vez em maior número nos navios para o Brasil, no final do século XIX para o século XX. É como se a imagem do emigrante estivesse associada à pobreza e ao infortúnio. Era necessário se deslocar dela.

Em matéria selecionada das inúmeras que se podia encontrar nos jornais da época, que tinham como tema a emigração em massa, destacamos uma em que podemos compreender de forma emblemática o argumento acima pontuado:

\begin{abstract}
Scenas da emigração
No domingo presenciamos uma scena da emigração na praça do Conde de São Bento, d'esta villa que nos comoveu. Um nosso infeliz conterrâneo, dos Arcos, regressava a pé de Lisboa, para a sua terra muito mal vestido, pois a roupa que dava algum dinheiro já a tinha vendido pelo caminho. Como vinha doente e a passar fome, cahiu aqui redondamente no chão, parecia que tinha sido acommetido de alguma apoplexia. 35
\end{abstract}

A matéria mostra, com clareza, a noção de miséria e pobreza do indivíduo vindo de Lisboa, de onde partia e chegava boa parte das embarcações que se deslocavam para o Brasil. A palavra emigração é destacada já no título: "scenas da emigração". Ironicamente, o indivíduo caiu justamente na Praça do Conde de São Bento, um dos emigrantes do Concelho de Santo Tirso que maior fortuna amealhou com o comércio no Pará. O indivíduo da matéria era retratado como "doente", "mal vestido", "infeliz conterrâneo", chegado em condições subhumanas, e encarnava a imagem dos inúmeros emigrados que voltavam desafortunados.

Por outro lado, ao falar do deslocamento de indivíduos com recursos, ou com algum capital simbólico, para o Brasil, as matérias de jornal não acionavam a palavra emigração. Falava-se que estes indivíduos "partiam de", "embarcavam de", "regressavam de", mas a eles não eram associadas expressões como "emigraram para". Assim, a chegada em Santo Tirso do sócio do barão de Monte Córdova, Joaquim Maria

${ }^{34}$ Centro de Memória da Amazônia. Fundo: Cartório Odon Rhossard, Ano 1907, Inventário de José Antonio Martins. Testamento transcrito a partir do Inventário.

35 Jornal de Santo Tirso, 17.11.1903, n.28. 
Leite, era assim descrita: "Na segunda-feira chegou a Lisboa, no vapor "madeirense", o snr. Joaquim Maria Leite, irmão do nosso amigo Manoel Maria Leite, chefe da antiga e importante Casa Comercial fundada no Pará pelo snr. Barão de Monte Córdova". ${ }^{36}$

Ou ainda, "Na segunda-feira, chegou a esta Villa, regressando do Pará, o nosso prezado amigo e conterrâneo, Francisco Martins Costa, partindo no mesmo dia para Monte Córdova, freguesia de sua naturalidade. Estimamos o regresso d'este nosso amigo a quem damos boas vindas". ${ }^{37}$ E, por fim, para citarmos uma última matéria, em que é referido um sobrinho do barão:

\begin{abstract}
Armando Martins Pinto, retirando-se para o Pará e não podendo como lhe cumpria despedir-se pessoalmente de todos os seus amigos que sempre lhe deram as mais inequívocas provas d'estima e amizade, e dos quais leva as mais profundas e gratas recordações, fal-o por este meio, oferecendo a todos o seu limitadíssimo préstimo n'aquella cidade, caixa do correio, n. $38.3^{38}$
\end{abstract}

Os três indivíduos acima citados migraram para o Pará atuando em atividades ligadas ao setor mercantil. A ida dos três para o Pará em momento algum é associada à palavra (e)migração. Eles "partem", "viajam", "regressam". A imagem é deslocada da emigração. As matérias de jornal parecem atualizar uma representação desses indivíduos desassociada do processo migratório. Cria-se a representação de que o "emigrante" é o outro, o pobre, o analfabeto. Aos demais indivíduos com riqueza e/ou capital simbólico são associados sentidos de pertença diferenciados da massa migratória que se desloca de Portugal. Não temos como saber em que medida a construção desses sentidos, são valores compartilhados pelos indivíduos que estão sendo citados nas matérias, mas a julgar pelas mesmas, as pessoas referidas eram conhecidas dos produtores da notícia, compartilhavam a amizade, a origem e as relações sociais e, possivelmente, as representações ali acionadas.

De algum modo, esse imigrante que se desloca para o Brasil, onde possui laços de família, de amizade, associado a setores do mercado de trabalho ligados ao comércio dos centros urbanos, realiza aquilo que Jorge Alves denominou "emigração privilegiada" reminiscente de uma presença colonial (ALVES, 1994, p. 45-46). A esta migração se distingue aquela dos trabalhadores que migravam para atuar nas fazendas rurais, nos serviços sem qualificação profissional, com baixos salários ou por conta própria, recebendo baixas diárias, de cuja imagem o emigrante privilegiado queria se distanciar e diferenciar.

A situação da família Martins se aproximava daquela emigração privilegiada, pelas condições sociais em que se encontrava e do capital simbólico construído. Desse modo, seus membros não pareciam se perceber na condição de emigrantes como parece sugerir a nota anteriormente citada, assinada pelo sobrinho do barão,

${ }^{36}$ Jornal de santo Tirso, 4.09.1902, n.18, fl 03. (Grifo do autor)

37 Jornal de santo Tirso, 21.08.1902, n.16, fl.02. (Grifo do autor)

${ }^{8}$ Jornal de Santo Tirso, 17.11.1904, n.28, flo3. (Grifo do autor) 
Armando Martins Pinto, onde o mesmo deixa claro que "está se retirando" para o Pará. A palavra (e)migração em momento algum aparece. A construção do status e do prestígio individual e familiar necessitava de uma espécie de dom, de representação distintiva de si (BOURDIEU, 1973) que passava pelo deslocamento da imagem da massa de imigrantes pobres.

\section{Considerações finais}

A história de José Antonio Martins e de seus irmãos nos mostra a trajetória de deslocamento migratório dos três irmãos mais velhos de uma família minhota, que chegaram a Belém como caixeiros, antes do boom da borracha. A capital paraense pode ter sido o destino de escolha, em função da história de sucesso de outros conterrâneos da mesma freguesia, Santo Tirso, que enriqueceram em terras paraenses e retornaram com grande prestígio para a localidade natal. Três irmãos que migraram para trabalhar em firmas comerciais e que abriram suas próprias casas de comércio de consignação e venda de produtos de importação e exportação em pleno auge da economia do ouro negro.

O barão nunca casou, os outros dois sim e, pelo menos um deles, com uma mulher paraense. Não eram sócios, mas mantinham sociedades comerciais com outros imigrantes portugueses, alguns deles da mesma freguesia, outros de localidades muito próximas, formando uma rede de negócios, que passava pela origem em comum. Embora não fossem todos sócios entre si, esses comerciantes se conheciam e mantinham relações pessoais. Manoel, por exemplo, nomeia em seu testamento, além de seu irmão Constantino, o sócio do barão, José Maria Leite, igualmente nascido em Santo Tirso, como seus possíveis inventariantes. Constantino também aparece no testamento do Barão como inventariante, assim como o comerciante de Braga, Domingos José Leite. Suas histórias se entrelaçam nas instituições beneméritas, de lazer e ajuda mútua de caráter nacional, bem como, as Associações de comércio, evidenciando um lugar específico de pertença marcado pela identidade nacional mas, ao mesmo tempo, pelas relações criadas e mantidas na e em meio à sociedade local. Construíram suas vivências neste universo, agregando status e prestígio. Casaram, abriram firmas, fizeram sociedade, articularam Associações, enfim, a agência destes indivíduos atualizou redes de múltiplas interações na sociedade de destino por eles eleita para viver a experiência migratória, ou deveria dizer "a partida", "a viagem", para acionar as representações de distinção em relação à massa de portugueses sem recursos que se deslocaram para o Pará nesse período.

Em relação ao Barão de Monte Córdova, bem como seus irmãos, a trajetória bem sucedida proporcionou fortuna em terras paraenses e, a estratégia familiar de deslocamento migratório dos varões, agregou riqueza, prestígio e mobilidade social à família Martins, no Pará, e em Portugal, alcançada a partir e, em meio, às redes familiares, de amizade, de negócios e associativas que foram sendo criadas ao longo da experiência de migração e retorno. 
Partimos da trajetória de um sujeito entrelaçado em diversas relações sociais, que acionou e interseccionou distintos marcadores: caixeiro, rico comerciante, barão, presidente de associação, solteiro, demente, irmão, tio e, como ele mesmo destacou em seu testamento, o mais antigo freguês do barbeiro Martiniano. A partir dele vimos a configuração dos projetos e redes individuais e coletivas que foram montadas, atualizando estratégias que minimizavam as incertezas do cotidiano em um novo lugar.

Outros imigrantes com outros marcadores sociais e inserções vão definir novas histórias. Muitas delas não passam pelo enriquecimento e o retorno à terra natal com distinção agregada a um capital econômico e simbólico. Alguns imigrantes iniciaram pela primeira vez o caminho dos deslocamentos, outros seguiram os passos já dados por um pai, um tio, um conterrâneo ou conhecido. Alguns saíam de suas aldeias como caixeiros e, passados alguns anos, retornavam como comerciantes, como ocorreu com o barão de Monte Córdova. Outros saíam como pescadores, lavradores, caixeiros e voltavam como indigentes, dependendo da ajuda de associações beneficentes para retornar.

Procuramos nesse artigo mostrar os diversos roteiros de vida desses sujeitos. Compreender através de fragmentos de suas trajetórias, a forma pela qual suas experiências estavam marcadas pelos limites da estrutura social, mas também pela agência, por escolhas realizadas em meio a representações e práticas sociais.

A partir da busca onomástica em vários corpos documentais compreendemos a mobilidade individual e familiar de José Antonio Martins no local de origem e de destino, as estratégias de inserção na cidade de Belém e os sentidos de uma identidade que se deslocou entre a figura do caixeiro e do comerciante bem sucedido, que agregou prestígio no título de barão, e que se reforçou na participação em associação de classe e nacionais. De algum modo, a participação nessas associações também ajudava a ressignificar essa identidade construindo a ideia de unidade de grupo, subsumindo as heterogeneidades e as diferenças existentes entre esses múltiplos imigrantes.

Contudo, rapidamente se percebem também as fissuras desses grupos quando os sujeitos buscam deslocar-se da imagem do português pobre, este sim "um imigrante", um desafortunado, em contraposição ao bem sucedido; a fissura se apresenta também nas disputas e conflitos que têm lugar na assunção das diretorias das associações.

Múltiplas foram as trajetórias que os moradores das aldeias portuguesas traçaram ao deixar o porto de Lisboa, de Leixões ou os vários portos clandestinos, para embarcar para o Pará. A história da família Martins em suas duas gerações foi marcada pelo trânsito entre esses portos. À viagem inicial saindo de Santo Tirso, para o porto da cidade de Belém, outras tantas se sucederam, indicando o movimento dos sujeitos. É o trânsito entre Portugal e Brasil, a formação e ampliação de recursos materiais, status e prestígio que vão marcar as várias gerações da família e as redes dinâmicas por eles (de)compostas. 


\section{Referências}

ALVES, Jorge Fernandes. Os brasileiros: emigração e retorno no Porto oitocentista. Porto: Universidade do Porto, 1994 .

ANDERSON, Benedict. Comunidades imaginadas. São Paulo: Companhia das Letras, 2008.

AVELINO, Yvone Dias. Imigração portuguesa e saúde: a fundação da beneficência portuguesa em São Paulo. In: ARRUDA, José Robson et al. De colonos a imigrantes: i(e)migração portuguesa para o Brasil. São Paulo: Alameda, 2013. p. 579-588.

BOURDIEU, Pierre. A ilusão biográfica. In: FERREIRA, Marieta de Moraes; AMARO, Janaína (Org.). Usos \& abusos da história oral. 8. ed. Rio de Janeiro: FGV, 2006.

BOURDIEU, Pierre. Condição de classe e posição de classe. In: AGUIAR, Neuma. Hierarquias em classes. Rio de Janeiro: Zahar, 1973. Cap.1.

BRETTELL, Caroline. Homens que partem, mulheres que esperam. Lisboa: Dom Quixote, 1991.

BURKER, Peter. Veneza e Amsterdã: um estudo das elites do século XVII. São Paulo: Brasiliense, 1990.

CANCELA, Cristina Donza et al. Os portugueses em Belém: patrimônio, origem e trajetória. In: ARRUDA, José Jobson A. et al. (Org.). De colonos a imigrantes: i(e)migração portuguesa para o Brasil. São Paulo: Alameda, 2013. p. 485-500.

CANCELA, Cristina Donza. Casamento e família em uma capital amazônica: (Belém 1870-1920). Belém: Açaí, 2011.

CANCELA, Cristina Donza. Uma cidade... muitas cidades: Belém na economia da borracha. In: BELTRÃO, Jane; VIEIRA JUNIOR, Antonio Otaviano. Conheça Belém, comemore o Pará. Fronteiras impertinentes. Belém: Editora da UFPA, 2008. p. 79-82.

CANCELA, Cristina Donza; BARROSO, Daniel Souza. Casamentos portugueses em uma capital da Amazônia: perfil demográfico, normas e redes sociais. Belém (1891-1920). História Unisinos, São Leopoldo, v. 15, n. 1, p. 6o-67, jan./abr. 2011.

CRUZ, Ernesto. História da associação comercial do Pará. Belém: UFPA, 1996.

FONSECA, Vítor. Beneficência e auxílio mútuo no associativismo português: Rio de Janeiro, 1903-1916. Revista Migrações: Número Temático Migrações entre Portugal e América Latina, Lisboa, n. 5, p. 221-237, out. 2009.

FRAGOSO, João. Homens de grossa aventura: acumulação e hierarquia na Praça Mercantil do Rio de Janeiro, 1790-1830. Rio de Janeiro: Civilização Brasileira, 1998.

FRUTUOSO, Maria Suzel. A emigração portuguesa e sua influência no Brasil: o caso de Santos (1850-1950). 1989. Dissertação (Mestrado em História)- FFLCH-USP, São Paulo, 1989.

GINZBURG, Carlo; CASTELNUOVO, Enrico; PONI, Carlo. O nome e o como: troca desigual e mercado historiográfico. In: A micro-história e outros ensaios. Lisboa: DIFEL, 1991. p. 169-178. 
GOMES, Ângela de Castro (Org.). Histórias de imigrantes e imigração no Rio de Janeiro. Rio de Janeiro: Sette Letras, 2000.

HEINZ, Flávio(Org.). Por outra história das elites. Rio de Janeiro: FGV, 2006.

HIDAKA, Ana Tereza Tomiko Vicente. Os infortúnios da imigração portuguesa: a benemérita liga portuguesa de repatriação (1908-1949). 2013. Dissertação (Mestrado em História Social da Amazônia) - Universidade Federal do Pará, Belém, 2013.

IMÍZCOZ, José Maria. Actores, redes, processos: reflexiones para uma historia más global. Revista da Faculdade de Letras, Porto, v. 5, n. 3, p. 115-140, 2004.

KUZNESOF, Elizabeth. A família na sociedade brasileira: parentesco, clientelismo e estrutura social, São Paulo, 1700-1980. Revista Brasileira de História: Famílias e Grupos de Convívio, São Paulo, fev. 1989.

LEITE, Joaquim da Costa Leite. O Brasil e a emigração portuguesa (1855-1914). In: FAUSTO, Boris (Org.). Fazer a América. São Paulo: EDUSP, 2000. p. 177-200.

LEVI, Giovanni. Usos da biografia. In: FERREIRA, Marieta de Moraes; AMARO, Janaína (Org.). Usos \& abusos da história oral. 8. ed. Rio de Janeiro: Editora FGV, 2006. p. 167-182.

LOBO, Eulália. Migração portuguesa no Brasil. São Paulo: Editora Hucitec, 2001.

MATOS, Maria Izilda. Âncora de emoções: a imigração portuguesa. Cadernos CERU, São Paulo, v. 19, n. 1, jun. 2008.

MATOS, Maria Izilda. Portugueses: deslocamentos, experiências e cotidianos. Bauru: EDUSC, 2013.

MATOS, Maria Izilda; LEITÃO, Alfredo. Portugueses em São Paulo: trabalho e ação política. Dimensões, Vitória, v. 26, p. 113-135, 2011.

MELO, Daniel; SILVA, Eduardo Caetano. Construção da nação e associativismo na emigração portuguesa. Lisboa: Instituto de Ciências Sociais, 2009.

MENDES, José Saccheta Ramos. Laços de sangue: privilégio e intolerância à imigração portuguesa no Brasil. Porto: CEPESE, 2010.

MENEZES, Lená Medeiros. Os indesejáveis: desclassificados da modernidade. Rio de Janeiro: EDUERJ, 1996.

MONTEIRO, Miguel. Migrantes, emigrantes e "brasileiros" de FAFE: territórios, itinerários e trajectórias (18341926). Edição de autor. Fafe: NEPS, 2000.

PEREIRA, Maria Manuela P. Caldas. Conde de São Bento: nome ilustre de Santo Tirso. Cadernos de Cultura, Santo Tirso, n. 2. 1984.

PEREIRA, Miriam Halpern. A política portuguesa de emigração (1850-1930). Bauru: Editora da Universidade do Sagrado Coração, 2002.

REIS, Arthur Cezar Ferreira. O seringal e o seringueiro: documentário da vida rural. Rio de Janeiro: Ministério da Agricultura, Serviço de Informação Agrícola, 1953.

REZNIK, Luiz; FERNANDES, Rui. Hospedarias de imigrantes nas Américas: a criação da hospedaria da llha das Flores. História, São Paulo, v. 33, n. 1, p. 234-253, jan./jun. 2014. 
RIBEIRO, Gladys. Mata-galegos: os portugueses e os conflitos de trabalho na primeira república velha. São Paulo: Brasiliense, 1990.

ROCHA-TRINDADE, Maria Beatriz; CAEIRO, Domingos. Portugal-Brasil: migrações e migrantes 1850-1930. Lisboa: INAPA, 2000.

SAMPAIO, Patrícia Maria Melo. Os fios de Ariadne: tipologia de fortunas e hierarquias sociais em Manaus. Manaus: Editora da Universidade do Amazonas, 1997.

SANTOS, Roberto. História econômica da Amazônia (1800-1920). São Paulo: T. A. Queiroz, 1980.

SERRÃO, Joel. A emigração portuguesa: sondagem histórica. Lisboa: Livros Horizonte, 1974. (Coleção horizonte, 12).

SILVA, Maria Beatriz Nizza. A mulher no contexto da imigração portuguesa no Brasil. Análise Social, Lisboa, v. 22, n. 92-93, p. 653-659, 1986.

SOUSA, Fernando; ROCHA, Ricardo. O distrito de Bragança (1835-2011). Disponível em: <http://www.cepese.pt/portal/pt/investigacao/working-papers/relacoes-externas-de-portugal/o-distrito-debraganca-1835-2011/distrito-de-braganassa-pdf>. Acesso em: 9 set. 2014.

TRUZZI, Oswaldo. Redes em processos migratórios. Tempo Social: Revista de Sociologia da USP, São Paulo, v. 20, n. 1, 2004 .

VASCONCELOS, Francisco. A nobreza portuguesa no século XIX. Porto: Centro de Estudos de Genealogia, Heráldica de Família de UMP, 2003.

WEINSTEIN, Barbara. A borracha na Amazônia: expansão e decadência (1850-1920). São Paulo: HUCITEC, 1993.

Recebido em 19/05/2015 - Aprovado em 03/03/2016. 